Louisiana State University

LSU Digital Commons

Faculty Publications

Department of Chemistry

$10-22-2019$

\title{
Purification of tag-free chlamydia trachomatis scc4 for structural studies using sarkosyl-assisted on-column complex dissociation
}

Thilini O. Ukwaththage

Louisiana State University

Octavia Y. Goodwin

Louisiana State University

Abigael C. Songok

Louisiana State University

Alexa M. Tafaro

Louisiana State University

Li Shen

LSU Health Sciences Center - New Orleans

See next page for additional authors

Follow this and additional works at: https://digitalcommons.Isu.edu/chemistry_pubs

\section{Recommended Citation}

Ukwaththage, T., Goodwin, O., Songok, A., Tafaro, A., Shen, L., \& MacNaughtan, M. (2019). Purification of tag-free chlamydia trachomatis scc4 for structural studies using sarkosyl-assisted on-column complex dissociation. Biochemistry, 58 (42), 4284-4292. https://doi.org/10.1021/acs.biochem.9b00665

This Article is brought to you for free and open access by the Department of Chemistry at LSU Digital Commons. It has been accepted for inclusion in Faculty Publications by an authorized administrator of LSU Digital Commons.

For more information, please contact ir@lsu.edu. 


\section{Authors}

Thilini O. Ukwaththage, Octavia Y. Goodwin, Abigael C. Songok, Alexa M. Tafaro, Li Shen, and Megan A. MacNaughtan 
Published in final edited form as:

Biochemistry. 2019 October 22; 58(42): 4284-4292. doi:10.1021/acs.biochem.9b00665.

\title{
Purification of Tag-Free Chlamydia trachomatis Scc4 for Structural Studies Using Sarkosyl-Assisted on-Column Complex Dissociation
}

\author{
Thilini O. Ukwaththage ${ }^{\dagger}$, Octavia Y. Goodwin ${ }^{\dagger}$, Abigael C. Songok ${ }^{\dagger}$, Alexa M. Tafaro $^{\dagger}$, Li \\ Shen $¥$, Megan A. Macnaughtan ${ }^{*}, \dagger$ \\ †Department of Chemistry, Louisiana State University, Baton Rouge, Louisiana 70803, United \\ States \\ ҒDepartment of Microbiology, Immunology, and Parasitology, Louisiana State University Health \\ Sciences Center, New Orleans, Louisiana 70112, United States
}

\section{Abstract}

Chlamydia trachomatis is an obligate intracellular bacterial pathogen that causes the most common sexually transmitted bacterial disease in the world. The bacterium has a unique biphasic developmental cycle with a type III secretion system (T3SS) to invade host cells. Scc4 is a class I T3SS chaperone forming a heterodimer complex with Scc1 to chaperone the essential virulence effector, CopN. Scc4 also functions as an RNA polymerase binding protein to regulate $\sigma^{66}$ dependent transcription. Aggregation and low solubility of 6X-histidine-tagged Scc4 and the insolubility of 6X-histidine and FLAG-tagged Scc1 expressed in Escherichia coli have hindered the high-resolution nuclear magnetic resonance (NMR) structure determination of these proteins and motivated the development of an on-column complex dissociation method to produce tag-free Scc4 and soluble FLAG-tagged Scc1. By utilizing a 6X-histidine-tag on one protein, the coexpressed Scc4-Scc1 complex was captured on nickel-charged immobilized metal affinity chromatography resin, and the nondenaturing detergent, sodium $N$-lauroylsarcosine (sarkosyl), was used to dissociate and elute the non-6X-histidine-tagged protein. Tag-free Scc4 was produced in a higher yield and had better NMR spectral characteristics compared to 6X-histidine-tagged Scc4, and soluble FLAG-tagged Scc1 was purified for the first time in a high yield. The backbone structure of Scc4 after exposure to sarkosyl was validated using NMR spectroscopy, demonstrating

\footnotetext{
*Corresponding Author: macnau@1su.edu.

Author Contributions

O.Y.G. and A.C.S. performed the initial screening and optimization of the sarkosyl-assisted on-column complex dissociation method. T.O.U. expressed and purified the proteins using standard Ni-IMAC and the on-column dissociation method with the aid of A.M.T., an undergraduate researcher in the laboratory. T.O.U. and M.A.M. performed the NMR experiments and analyzed data. T.O.U., L.S., and M.A.M. contributed to writing the manuscript.

Supporting Information

The Supporting Information is available free of charge on the ACS Publications website at DOI: 10.1021/acs.bio-chem.9b00665. SDS-PAGE analysis of GST-Scc4, SDS-PAGE analysis of His6-Scc4, SDS-PAGE analysis of Scc4-Scc1-His6, complete SDS-PAGE gels from Figure 2, chromatogram of sarkosyl gradient elution, SDS-PAGE analysis of reloaded tag-free Scc4, and SDS-PAGE analysis of Scc1-FT solubility (PDF)

Accession Codes

Scc4, UniprotKB O84670; Scc1, UniprotKB O84090; CopN, UniprotKB O84091, RpoB, UniprotKB P0CE09, RpoD UniprotKB P18333.

The authors declare no competing financial interest.
} 
the usefulness of the method to produce proteins for structural and functional studies. The sarkosyl-assisted on-column complex dissociation method is generally applicable to protein complexes with high affinity and is particularly useful when affinity tags alter the protein's biophysical properties or when coexpression is necessary for solubility.

\section{Graphical Abstract}

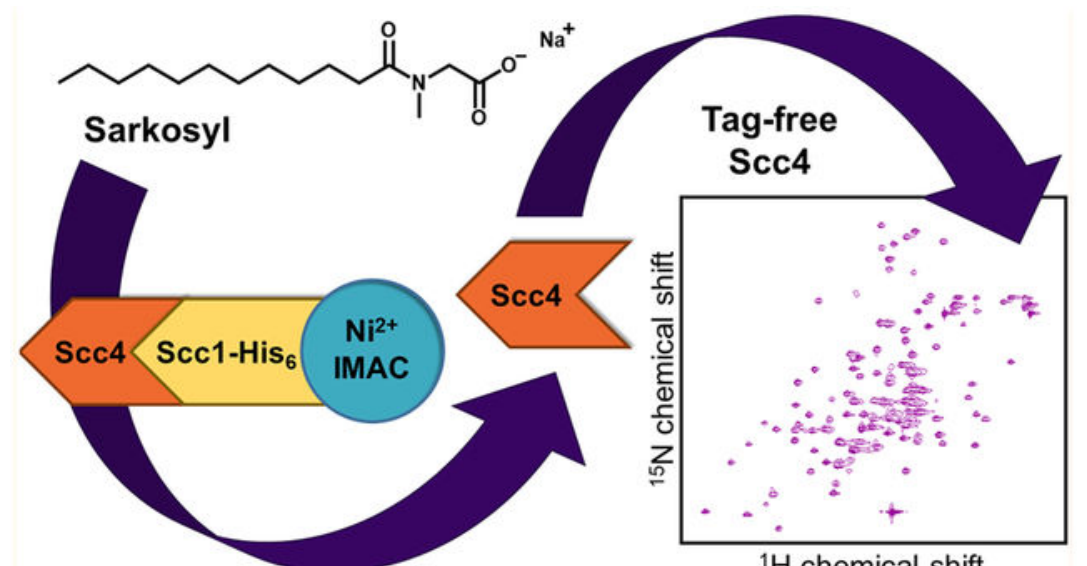

${ }^{1} \mathrm{H}$ chemical shift

Chlamydia trachomatis $(C T)$ is an obligate intracellular bacterial pathogen that causes the most common sexually transmitted bacterial disease in the world, with over 90 million infections each year. ${ }^{1,2}$ In the United States alone, 1.7 million people were infected in 2017 with a $6.5 \%$ increase in reported cases from 2016 to $2017 .{ }^{3} C T$ strains can be divided into at least 18 serovars, of which serovars A-C associate with ocular infections and serovars L1L3 cause lymphogranuloma venereum. Serovars D-K cause sexually transmitted infections that result in severe reproductive health complications when left untreated. ${ }^{4,5}$ Moreover, $C T$ infections facilitate the transmission of other sexually transmitted diseases such as HIV. ${ }^{6} C T$ has a unique developmental cycle where infectious elementary bodies (EBs) utilize a type III secretion system (T3SS) to introduce virulence factors into the host's cytosol and promote invasion into columnar epithelial cells. ${ }^{6,7}$ After internalization EBs differentiate into reticulate bodies (RBs), which are noninfectious and metabolically active cells that rapidly replicate. In the later stage of the developmental cycle, RBs transform into EBs, and the EBs are released from the host cell to infect neighboring cells. 6,8

Scc4 (specific chlamydia chaperone 4, formerly CT663, UniprotKB O84670) is a bifunctional protein that plays a vital role in the developmental cycle of $C T$ as a class 1 T3SS chaperone and a transcription factor. ${ }^{9-13}$ As a T3SS chaperone, Scc4 forms a heterodimer complex with Scc1 (specific chlamydia chaperone 1 or CT088, UniprotKB O84090). ${ }^{12,13}$ Scc4 and Scc1 are small cytosolic proteins that bind and stabilize the Chlamydial outer protein N (CopN or CT089, UniprotKB O84091) prior to its secretion. 9,12,13 CopN is an effector protein secreted by the T3SS and plays an essential role in bacterial virulence by interfering with the microtubule network. ${ }^{9,14,15}$ In addition to the chaperone function, Scc 4 acts as a transcription factor by directly binding the $\beta$ subunit (RpoB, UniprotKB P0CE09) and the primary sigma factor 66 ( $\sigma^{66}$ or RpoD, UniprotKB 
P18333) of the RNA polymerase holoenzyme. ${ }^{10}$ These interactions specifically regulate $\sigma^{66}$ dependent transcription, which controls housekeeping gene expression during the developmental cycle of $C T \cdot{ }^{10}$ To advance our understanding of Scc4 and the mechanisms that control its functions, a high-resolution three-dimensional structure of Scc4 is needed. Scc4 is also a good therapeutic target to treat $C T$ due to the essential and multiple roles of Scc4 in $C T$ propagation and pathogenesis. High-resolution structures of Scc4 alone and in complex with Scc1, CopN, RpoB, and $\sigma^{66}$ would greatly aid drug design and development to target one or both of Scc4's functions. Scc4 is a unique protein to Chlamydia with little sequence similarity outside of the genus, offering the potential for highly specific antibacterial drugs. Even though Scc4 lacks sequence homology to other proteins, it has structural homology to several bacterial T3SS chaperones, and a good structural model can be produced of Scc4 and its chaperone partner, Scc1 $1{ }^{13}$ However, Scc4 has no sequence or structural similarity to any known transcription factors, providing the possibility of a new structural fold for this function. Our group has been pursuing the high-resolution structure of Scc4 to investigate its transcription factor structure and function.

In order to determine the high-resolution structures of proteins, large quantities of pure protein are needed in the native conformation with high solubility and low aggregation tendency. The most common strategy to achieve these criteria is to express the recombinant gene in Escherichia coli with a purification tag and purify the protein with the corresponding

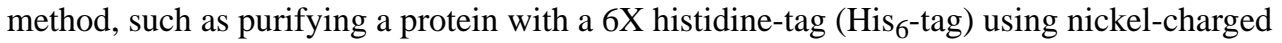
immobilized metal affinity chromatography (Ni-IMAC). ${ }^{16}$ Purification tags can interfere with the native structure, activity, and physical properties of a protein. The tags can also preclude high-resolution structure determination by X-ray crystallography by interfering with crystallization or nuclear magnetic resonance spectroscopy (NMR) by inducing aggregation. We previously reported that an $\mathrm{N}$-terminal $\mathrm{His}_{6}$-tag on $\mathrm{Scc} 4$ causes aggregation and a $C$-terminal His $_{6}$-tag or FLAG-tag on Scc1 causes insolubility. ${ }^{13}$ One strategy to overcome the deleterious effects of affinity tags is to remove the tag by inserting a selective protease recognition sequence between the tag and the protein of interest. This strategy typically leaves behind a few residues from the protease recognition sequence, but a few methods have been developed to produce tag-free proteins. ${ }^{17,18}$ One potential problem with removing the tag is low protease activity due to the insolubility of the protein or steric hindrance from the protein of interest. The ideal situation for a soluble protein is to express it without a purification tag if a suitable purification method is available.

In this study, we developed a purification method to obtain tag-free proteins; specifically, tag-free Scc4, an RNA polymerase binding protein from $C T$. By taking advantage of the high-affinity between Scc4 and Scc1, the heterodimer T3SS chaperone complex was coexpressed and immobilized on Ni-IMAC resin via a His $6_{6}$-tag on Scc1. The nondenaturing detergent, sodium $N$-lauroylsarcosine (sarkosyl), was found to dissociate the complex without disrupting the immobilized nickel and $\mathrm{His}_{6}$-tag interaction, allowing tag-free Scc4 to be separated. The yield of tag-free Scc4 by way of sarkosyl-assisted on-column complex dissociation was 6-7 times higher than $\mathrm{His}_{6}$-tagged $\mathrm{Scc}_{4}\left(\mathrm{His}_{6}{ }_{-} \mathrm{Scc} 4\right)$ using standard NiIMAC, likely due to the increased solubility of tag-free Scc4. We show that sarkosyl does not alter the backbone structure of Scc 4 and the quality of the $1 \mathrm{H}, 15 \mathrm{~N}$ heteronuclear single quantum coherence (HSQC) spectrum of tag-free Scc4 is better than $\mathrm{His}_{6}-\mathrm{Scc} 4$ for NMR 
structure determination. The method can also be implemented reciprocally to produce Scc1 with a $C$-terminal FLAG tag (Scc1-FT) using the coexpressed His 6 -Scc4-Scc1-FT complex. We anticipate that this method can be applied to other proteins in tight-binding complexes to produce tag-free proteins for structural and functional studies.

\section{MATERIALS AND METHODS}

\section{Materials.}

The recombinant expression plasmids, pA-CYCScc1-His 6 , pET28Scc4, and pCDFScc4, were described previously. ${ }^{13}$ Plasmid pScc1-FT ${ }^{19}$ was kindly provided by Dr. Ken Fields (University of Kentucky, College of Medicine, Lexington, Kentucky, USA). These plasmids encode Scc1 with a $C$-terminal His $_{6}$-tag that is removable with tobacco Etch virus protease (Scc1-His 6 ), tag-free Scc4, Scc4 with an $\mathrm{N}$-terminal $\mathrm{His}_{6}$-tag $\left(\mathrm{His}_{6}\right.$-Scc4 ), and Scc1 with a $C$-terminal FLAG tag (Scc1-FT), respectively. All water used was supplied from a Millipore Direct-Q 3 ultrapure water system. All solutions containing sodium dodecyl sulfate (SDS), sarkosyl, and glycerol are reported as percentage mass/volume. Other reagents reported as percentages, such as methanol, water, acetic acid, and $\mathrm{D}_{2} \mathrm{O}$, are in units of percentage by volume unless otherwise stated.

\section{Protein Expression of Scc4-Scc1 Complexes and $\mathrm{His}_{6}-\mathrm{Scc} 4$.}

The Scc4-Scc1-His 6 complex and $\mathrm{His}_{6}$-Scc4 were expressed in E. coli BL21-Gold (DE3) and T7 Express lysY/I ${ }^{9} E$. coli cells, respectively, as described by Shen et al. ${ }^{13}{ }^{15} \mathrm{~N} /{ }^{13} \mathrm{C}$ labeled Scc4-Scc1-His 6 complex and ${ }^{15} \mathrm{~N}$-labeled $\mathrm{His}_{6}$-Scc4 were produced following the isotopic labeling method described by Marley et al. ${ }^{20}$ where the cells are grown in rich medium and then exchanged into minimal medium supplemented with $15 \mathrm{NH}_{4} \mathrm{Cl}\left({ }^{15} \mathrm{~N}, 99 \%\right)$ and $13 \mathrm{C}$-glucose $\left(\mathrm{U}_{-}{ }^{13} \mathrm{C}_{6}, 99 \%\right)$ before induction. The minimal growth medium was $\mathrm{M} 9$ salts $\left(50 \mathrm{mM} \mathrm{Na}_{2} \mathrm{HPO}_{4}, 20 \mathrm{mM} \mathrm{KH}{ }_{2} \mathrm{PO}_{4}, 10 \mathrm{mM} \mathrm{NaCl}, 18 \mathrm{mM}(1.0 \mathrm{~g} / \mathrm{L}){ }^{15} \mathrm{NH}_{4} \mathrm{Cl}\right), 2 \mathrm{mM}$ $\mathrm{MgSO}_{4}, 0.1 \mathrm{mM} \mathrm{CaCl} 2,1 \mathrm{X} \mathrm{BME}$ vitamins, $3.0 \mathrm{mM}(1.0 \mathrm{mg} / \mathrm{L})$ thiamine hydrochloride, $1 \mathrm{X}$ trace metal solution, ${ }^{21}$ and $22 \mathrm{mM}(4.0 \mathrm{~g} / \mathrm{L})$ glucose or ${ }^{13} \mathrm{C}$-glucose with the appropriate antibiotics. For coexpressing the Scc4-Scc1-His ${ }_{6}$ complex from pET28Scc4 and pACYCScc1-His $6,50 \mu \mathrm{g} / \mathrm{mL}$ kanamycin and $35 \mu \mathrm{g} / \mathrm{mL}$ chloramphenicol were used; and for expressing $\mathrm{His}_{6}$-Scc4 from pCDFScc $4,50 \mu \mathrm{g} / \mathrm{mL}$ spectinomycin was used. To produce ${ }^{15} \mathrm{~N} /$ ${ }^{13} \mathrm{C}$-labeled protein, the bacterial cultures were first grown in LB medium until an optical density of 0.6 at $600 \mathrm{~nm}$ was reached. The medium was then exchanged to minimal medium, and the bacterial cultures were incubated at $37^{\circ} \mathrm{C}$ with $250 \mathrm{rpm}$ shaking for $1 \mathrm{~h}$ before 0.5 $\mathrm{mM}$ isopropyl $\beta \mathrm{c} 1$-thiogalactopyranoside (IPTG) was added. The minimal medium cultures were incubated at $16^{\circ} \mathrm{C}$ with $250 \mathrm{rpm}$ shaking for $16 \mathrm{~h}$. From all cultures, cells were harvested by centrifugation at $3000 \mathrm{~g}$ for $20 \mathrm{~min}$ at $4{ }^{\circ} \mathrm{C}$ and suspended in $15 \mathrm{~mL}$ of Tris wash buffer (20 mM tris(hydroxymethyl)-aminomethane hydrochloride (Tris), $300 \mathrm{mM}$ $\mathrm{NaCl}, 2 \mathrm{mM}$ imidazole, and $5 \%$ glycerol at $\mathrm{pH} 8.0$ ). The cells were either stored at $-80{ }^{\circ} \mathrm{C}$ or processed for protein purification. The same expression procedures were used to produce unlabeled and $15 \mathrm{~N} /{ }^{13} \mathrm{C}$-labeled $\mathrm{His}_{6}$-Scc4-Scc1-FT complex using pCDFScc4 and pScc1FT in E. coli T7 Express cells with the appropriate antibiotics ( $50 \mu \mathrm{g} / \mathrm{mL}$ spectinomycin, $100 \mu \mathrm{g} / \mathrm{mL}$ ampicillin). 


\section{Protein Purification and SDS-PAGE Analysis.}

Suspension of bacterial cell pellets $(15 \mathrm{~mL})$ from the expressions were prepared for lysis by adding 2 Pierce EDTA free protease inhibitor mini tablets, $1.7 \mathrm{~mL}$ of $10 \times$ BugBuster protein extraction reagent, and $0.75 \mu \mathrm{L}$ of Benzonase nuclease. The cells were lysed using a French pressure cell followed by centrifugation at $25000 \mathrm{~g}$ for $30 \mathrm{~min}$ at $4{ }^{\circ} \mathrm{C}$ to obtain soluble protein in the cleared lysate. The cleared lysate containing either Scc4-Scc1-His 6 , His $_{6}{ }^{-}$ Scc4-Scc1-FT, or His6-Scc4 was immediately loaded onto $4 \mathrm{~mL}$ of Ni-IMAC resin $(1 \mathrm{~cm}$ i.d. column) at a flow rate of $1 \mathrm{~mL} / \mathrm{min}$ using a fast protein liquid chromatography system (FPLC). The captured proteins were washed with $20 \mathrm{~mL}$ of Tris wash buffer and eluted with $20 \mathrm{~mL}$ of Tris elution buffer (20 mM Tris, $300 \mathrm{mM} \mathrm{NaCl}, 500 \mathrm{mM}$ imidazole, and $5 \%$ glycerol at $\mathrm{pH} 8.0)$ at a flow rate of $2 \mathrm{~mL} / \mathrm{min}$. The eluted proteins were detected using absorbance at $280 \mathrm{~nm}\left(A_{280}\right)$ and pooled from $1 \mathrm{~mL}$ fractions (typically 5-6 mL). The Tris elution buffer was exchanged to the desired buffer using $15 \mathrm{~mL}$ of $P 4$ gel (polyacrylamide beads in a $1 \mathrm{cmi}$.d. column) at a flow rate of $0.5 \mathrm{~mL} / \mathrm{min}$ with $1 \mathrm{~mL}$ fractions. The protein fractions were combined based on $A_{280}$ and analyzed using the Bradford protein assay following the manufacturer's 96-well plate instructions (Pierce Comassie Plus Assay Kit, Thermo Fisher Scientific). The results from the Bradford protein assay are reported in the results as mg protein or complex per L culture. Samples taken during the purification of the proteins, including the purified proteins, were analyzed by sodium dodecyl sulfatepolyacrylamide gel electrophoresis (SDS-PAGE). Sample aliquots $(10 \mu \mathrm{L})$ were mixed with $10 \mu \mathrm{L}$ of $2 \mathrm{X}$ Laemmli buffer with $5 \%$ (by volume) of $\beta$-mercaptoethanol, heated at $95{ }^{\circ} \mathrm{C}$ for $5 \mathrm{~min}$, and loaded into 4-20\% Tris/glycine gels. The gels were run at $120 \mathrm{~V}$ for $45 \mathrm{~min}$ in running buffer ( $25 \mathrm{mM}$ Tris, $192 \mathrm{mM}$ glycine, $0.1 \%$ SDS, pH 8.3 buffer) followed by staining with brilliant blue R-250 solution $(0.1 \%(\mathrm{~m} / \mathrm{V})$ brilliant blue R-250 dye, $50 \%$ methanol, $40 \%$ water, and $10 \%$ acetic acid). After destaining in 50\% water, $40 \%$ methanol, $10 \%$ acetic acid, the gels were imaged using a Bio-Rad Gel Doc EZ System.

\section{On-Column Complex Dissociation of Scc4-Scc1-His 6 .}

Various reagents were tested to dissociate tag-free Scc4 from immobilized Scc4-Scc1-His 6 complex. Purified Scc4-Scc1-His 6 complex in Tris buffer $(20 \mathrm{mM}$ Tris, $300 \mathrm{mM} \mathrm{NaCl}, 5 \%$ glycerol, $\mathrm{pH}$ 8.0) was loaded onto $1 \mathrm{~mL}$ of Ni-IMAC resin and briefly washed with Tris buffer. In separate experiments, the dissociation of tag-free Scc4 from the immobilized complex was tested by washing the resin with $10 \mathrm{~mL}$ of $6 \mathrm{M}$ urea, $8 \mathrm{M}$ urea, $2 \% \mathrm{SDS}$, or $0.5 \%$ sarkosyl in Tris buffer. Any remaining protein was eluted from the column with $10 \mathrm{~mL}$ of Tris buffer with $500 \mathrm{mM}$ imidazole. SDS-PAGE analysis was used to determine the protein content in the dissociation and elution fractions.

To estimate the minimum concentration of sarkosyl needed to dissociate tag-free Scc 4 from the immobilized Scc4-Scc1-His 6 complex, a gradient elution from 0-1\% sarkosyl in $50 \mathrm{mM}$ sodium phosphate, $300 \mathrm{mM}$ sodium chloride, $\mathrm{pH} 7.4$ buffer at a flow rate of $1 \mathrm{~mL} / \mathrm{min}$ over 10 min was performed using an FPLC. The dissociation of Scc4 was monitored by $A_{280}$. The minimum concentration of sarkosyl was estimated as the sarkosyl concentration corresponding to the maximum $A_{280}$ of the Scc4 elution peak. 


\section{Protein Purification by Sarkosyl-Assisted on-Column Complex Dissociation.}

Tag-free Scc4 was purified by on-column dissociation of the Scc4-Scc1-His 6 complex by selective elution of Scc4 with 0.5\% sarkosyl buffer followed by elution of Scc1-His 6 with $500 \mathrm{mM}$ imidazole buffer. Scc4-Scc1-His 6 (purified or in cleared lysate) was loaded onto 4 $\mathrm{mL}(1 \mathrm{~cm}$ i.d. column) of Ni-IMAC resin using an FPLC and a flow rate of $1 \mathrm{~mL} / \mathrm{min}$. Subsequent wash and elution steps used a flow rate of $2 \mathrm{~mL} / \mathrm{min}$, and the elution samples were collected as $1 \mathrm{~mL}$ fractions and pooled based on $A_{280}$. The immobilized complex was washed with $20 \mathrm{~mL}$ of Tris wash buffer. Tag-free Scc4 was eluted with $20 \mathrm{~mL}$ of Tris wash buffer containing $0.5 \%$ sarkosyl. The remaining immobilized Scc1-His 6 was either eluted with $10 \mathrm{~mL}$ of $500 \mathrm{mM}$ imidazole elution buffer or used to purify excess tag-free Scc 4 from the lysate flow-through. For purifying excess tag-free Scc4, the immobilized Scc1-His 6 was washed with $20 \mathrm{~mL}$ of wash buffer to remove residual sarkosyl, the lysate flow-through was reloaded at $1 \mathrm{~mL} / \mathrm{min}$, and tag-free Scc 4 was eluted with $0.5 \%$ sarkosyl buffer. To remove trace quantities of Scc1-His ${ }_{6}$ from the purified tag-free Scc4, the Scc4 elution was filtered through $4 \mathrm{~mL}$ of fresh Ni-IMAC resin. To remove the sarkosyl from the purified tag-free $\mathrm{Scc} 4$, the sample was diluted 5-fold with $50 \mathrm{mM}$ sodium phosphate, $\mathrm{pH} 7.3$ buffer to reduce the sarkosyl concentration below the critical micelle concentration $(\mathrm{cmc})$. The diluted solution was then concentrated to $4 \mathrm{~mL}$ using a $10 \mathrm{kDa}$ molecular weight cutoff centrifugal filter, and exchanged to $50 \mathrm{mM}$ sodium phosphate, $\mathrm{pH} 7.3$ buffer using $15 \mathrm{~mL}$ of $P 4$ gel. To determine if the dissociation of the complex was independent of the His 6 -tag position, Scc1FT-His ${ }_{6}$-Scc4 (purified or in cleared lysate) was treated identically as described for sarkosylassisted on-column dissociation of the Scc4-Scc1-His 6 complex. In this situation, Scc1-FT elutes with the $0.5 \%$ sarkosyl buffer and $\mathrm{His}_{6}$-Scc4 elutes with the $500 \mathrm{mM}$ imidazole buffer.

\section{NMR Spectroscopy.}

${ }^{1} \mathrm{H}_{-}{ }^{15} \mathrm{~N}$ HSQC spectra of $\mathrm{His}_{6}$-Scc4 and tag-free Scc4 were collected to determine if the proteins were suitable for NMR structure determination. NMR samples of Scc4 were prepared by desalting approximately $2 \mathrm{mg}$ of protein into various buffers using a $P 4$ gel column and concentrating to $250 \mu \mathrm{L}$ using $10 \mathrm{kDa}$ molecular weight cutoff centrifugal filters. The samples were transferred to $5 \mathrm{~mm} \mathrm{D}_{2} \mathrm{O}$ susceptibility matched Shigemi tubes, and $5 \mu \mathrm{M}$ sodium 3-(trimethylsilyl)-1-propanesulfonate (DSS) and $10 \% \mathrm{D}_{2} \mathrm{O}$ were added for chemical shift referencing and locking, respectively. The $2 \mathrm{D}{ }^{1} \mathrm{H}-{ }^{15} \mathrm{~N}$ HSQC spectra were collected of $0.5 \mathrm{mM} \mathrm{Scc} 4$ samples on a Bruker Advance III HD $500 \mathrm{MHz}$ instrument (16-64 scans, 256 increments $)$ at $300 \mathrm{~K}\left(27^{\circ} \mathrm{C}\right)$.

\section{RESULTS AND DISCUSSION}

\section{Suitability of $\mathrm{His}_{6}-\mathrm{Scc} 4$ for NMR Structure Determination.}

Since crystallographic trials of various Scc 4 constructs have thus far been unsuccessful, the suitability of $\mathrm{His}_{6}$-Scc4 for NMR structure determination was evaluated. Structure determination by NMR requires that the protein be ${ }^{13} \mathrm{C} /{ }^{15} \mathrm{~N}$-labeled, soluble at $0.2-1 \mathrm{mM}$ concentrations, and $\searrow 95 \%$ pure. These requirements are typically achieved by testing various constructs of the protein; for example, altering the purification tag and optimizing the sample buffer conditions to reach high solubility. The expression and purification of GSTScc4 (formerly GST-CT663) ${ }^{10}$ was tested, but low solubility of the protein led to low yields 
(Figure $\mathrm{S} 1$ ). $\mathrm{His}_{6}$-Scc4 was produced in $15 \mathrm{~N}$-supplemented minimal medium with a moderate yield of $2-3 \mathrm{mg}$ protein per L culture (Figure S2). Figure 1 shows the $2 \mathrm{D}{ }^{1} \mathrm{H}_{-}{ }^{15} \mathrm{~N}$ HSQC spectrum of $0.5 \mathrm{mM} \mathrm{His}_{6}$-Scc 4 in $50 \mathrm{mM}$ sodium phosphate, $\mathrm{pH} 7.3$ buffer. The peak dispersion of $\mathrm{His}_{6}-\mathrm{Scc} 4$ is good and indicates that the protein is folded, but only $75 \%$ of the expected backbone amide $(\mathrm{N}-\mathrm{H})$ correlation peaks are visible (typically $\geq 90 \%$ is desirable). The spectrum also shows heterogeneous peak intensities and broad peaks clustered in the center of the spectrum. These features indicate that $\mathrm{His}_{6}-\mathrm{Scc} 4$ is aggregating, forming soluble oligomers, or partially unfolding under these conditions, consistent with published size exclusion chromatographic analysis of $\mathrm{His}_{6}-\mathrm{Scc} 4$, which shows a size dependence with buffer conditions (dimers and trimers) and species greater than $150 \mathrm{kDa}$ in phosphate buffer.

13 Other conditions were tested by varying the protein concentration, salt concentration, $\mathrm{pH}$, and buffering reagent with no better results, so a different construct of Scc4 was needed to proceed with NMR structure determination.

\section{Sarkosyl-Assisted on-Column Complex Dissociation of Scc4-Scc1-His 6 To Produce Tag- Free Scc4.}

Based on early experiments in our laboratory with ${ }^{15} \mathrm{~N}$-labeled tag-free Scc 4 , the ${ }^{1} \mathrm{H}_{-}{ }^{15} \mathrm{~N}$ HSQC spectrum looked promising but was dismissed due to the labor-intensive purification of tag-free Scc4. After disappointing results with other Scc4 constructs, alternative methods were explored to produce tag-free Scc4. It has been shown that Scc4 and Scc1-His 6 express well in E. coli and copurify as a 1:1 molar ratio complex. ${ }^{13}$ The dissociation of this complex would provide a straightforward method to purify tag-free Scc4.

Scc4-Scc1-His 6 was captured on Ni-IMAC resin to determine whether the complex could be dissociated using some common reagents. Dissociation of Scc1-His 6 and tag-free Scc4 is challenging due to the high affinity of the complex, which we estimate to have a dissociation constant in the sub-nM range based on published size exclusion chromatographic data and the $1: 1$ stoichiometry of the copurified complex. ${ }^{13}$ To succeed in isolating tag-free Scc4, the reagent should only disrupt the interaction between Scc4 and Scc1-His 6 and not affect the immobilized nickel and His $_{6}$-tag interaction. The Scc4-Scc1-His 6 complex was produced in high yield (12-15 mg of complex per L culture using LB medium or minimal medium) and purified as a 1:1 molar ratio complex (Figure S3). The complex was exchanged into an imidazole-free buffer using $P 4$ gel and immobilized onto fresh Ni-IMAC resin. Figure 2 shows an SDS-PAGE gel of the imidazole-eluted proteins after the captured Scc4-Scc1-His 6 complex was washed with $6 \mathrm{M}$ urea (lane 4), $8 \mathrm{M}$ urea (lane 5), 2\% SDS (lane 6), and 0.5\% sarkosyl (lane 7). Urea is a common denaturing agent used for unfolding protein by direct interaction with the protein or indirect interaction with the solvation of hydrophobic groups. 22 Surprisingly, the urea-washed samples did not fully dissociate the complex as both Scc4 and $\mathrm{Scc}_{1-\mathrm{His}_{6}}$ were present in the imidazole elution samples. After washing with $2 \%$ SDS or $0.5 \%$ sarkosyl, the imidazole elution samples only contained Scc1-His ${ }_{6}$ confirming the dissociation of the Scc4-Scc1-His 6 complex. SDS and sarkosyl are negatively charged, amphiphilic detergents, which can affect the hydrophobic interactions of proteins. ${ }^{23}$ Sarkosyl is milder than SDS, ${ }^{23}$ causing less protein denaturation, and has been used to disrupt protein aggregates and strong protein-protein interactions without affecting the protein's function. ${ }^{24,25}$ For the initial tests, the protein that eluted in the wash steps (with 6 
$\mathrm{M}$ urea, $8 \mathrm{M}$ urea, and 2\% SDS) were not collected or analyzed by SDS-PAGE; however, the $0.5 \%$ sarkosyl test was repeated in order to collect both the protein eluted with sarkosyl (Figure 2, lane 9) and the protein eluted with imidazole (Figure 2, lane 7). The SDS-PAGE analysis of these samples shows that tag-free Scc 4 cleanly and completely dissociates from Scc1-His 6 with the $0.5 \%$ sarkosyl buffer.

The minimum concentration of sarkosyl needed to disrupt the Scc4-Scc1-His 6 complex was estimated by monitoring the elution of tag-free Scc4 from the immobilized complex with a gradient of sarkosyl concentrations (0-1\% sarkosyl in $50 \mathrm{mM}$ sodium phosphate, $300 \mathrm{mM}$ sodium chloride, $\mathrm{pH} 7.4$ buffer over $10 \mathrm{~mL}$ ). Tag-free Scc4 starts eluting at $3.0 \mathrm{~mL}$ with a maximum $A_{280}$ at $4.4 \mathrm{~mL}$ in the chromatogram (Figure S5). These volumes correspond to 0.30 and $0.44 \%$ sarkosyl in the running buffer. Interestingly, the cmc of sarkosyl is reported to depend on the $\mathrm{pH}$ and buffer composition with a range of values in water from 0.10 to $0.28 \%$ (pH 7-8.5, 3.3-9.5 mM) and a value of $0.18 \%(6.2 \mathrm{mM})$ in $20 \mathrm{mM}$ sodium phosphate, $\mathrm{pH} 7$ buffer (all measured by surface tension). ${ }^{26,27}$ The $\mathrm{cmc}$ of sarkosyl measured by conductivity in water at $\mathrm{pH} 8.5$ is reported to be $0.38 \%(13 \mathrm{mM}) .{ }^{26}$ Comparing our results to the published cmc values suggests that micelle formation is necessary to dissociate tag-free Scc4 from the complex; although, the interpretation is limited by the unknown effects of the buffer composition and Ni-IMAC resin on sarkosyl's cmc. Other reports that use sarkosyl to disrupt protein-protein interactions report concentrations from $0.1-0.5 \%$ with different optimal concentrations for different complexes. ${ }^{25,28,29}$ A concentration of $0.5 \%$ sarkosyl was chosen for the on-column dissociation of the Scc4-Scc1-His ${ }_{6}$ complex to ensure efficient elution of tag-free Scc4.

The sarkosyl-dissociation method was used to purify tag-free Scc4 and Scc1-His 6 from cleared lysate containing the coexpressed proteins. The relative amount of tag-free Scc4 expressing from pET28Scc4 and Scc1-His ${ }_{6}$ expressing from pACYCScc1-His 6 in E. coli cells is variable with Scc1-His 6 being less than tag-free Scc4, likely due to the pACYC184 plasmid having a lower copy number than the pET28 plasmid. Comparing the induction of protein expression in Figure 3, lanes 1 and 2, tag-free Scc4 is overexpressed with lower quantities of Scc1-His 6 . In this situation, excess tag-free Scc4 flows through the Ni-IMAC resin with the unbound proteins in the cleared lysate. After dissociating tag-free Scc4 from Scc1-His 6 with $0.5 \%$ sarkosyl, the Ni-IMAC-bound Scc1-His ${ }_{6}$ was used to directly capture excess Scc4 from the lysate flow through. The immobilized Scc1-His ${ }_{6}$ is washed with Tris wash buffer to remove any residual sarkosyl, and the lysate flow through containing excess tag-free Scc4 is reloaded, captured, and eluted with sarkosyl buffer. The reloading of the lysate flow-through can be done several times to purify all of the excess tag-free Scc4 (Figure S6). The yield of tag-free Scc 4 is $12-15 \mathrm{mg}$ of protein per L culture in LB and minimal media, which is 6-7 times the yield of $\mathrm{His}_{6}$-Scc4 expressed alone (2-3 mg of protein per L culture). As shown in Figure 3, lane 3, the purified tag-free Scc4 can sometimes contain small amounts of Scc1-His 6 . Since this observation is not seen every time, the coeluting Scc1-His 6 likely originates from the dissociation of Scc4-Scc1-His 6 tetramer ${ }^{13}$ in situations where the Ni-IMAC capacity is low. This hypothesis is based on previous work showing Scc4-Scc1-His ${ }_{6}$ forms tetramers in Tris buffer. ${ }^{13}$ The contaminating Scc1-His 6 protein is easily removed by passing the sample through fresh Ni-IMAC resin to obtain highly pure tag-free Scc4 (Figure 3, lane 4). Finally, Scc1-His 6 can be eluted with 
$500 \mathrm{mM}$ imidazole buffer (Figure 3, lane 7). The eluted Scc1-His 6 is pure with no traces of tag free Scc4, demonstrating that $0.5 \%$ sarkosyl efficiently elutes tag-free Scc4. Scc1-His 6 has good solubility in the Tris elution buffer with $500 \mathrm{mM}$ imidazole, but the protein precipitates as the imidazole concentration is lowered or when the buffering reagent is changed.

\section{Sarkosyl-Assisted on-Column Complex Dissociation with the His 6 -Tag Interchanged.}

The His $_{6}$-Scc4-Scc1-FT complex was produced to demonstrate that the sarkosyl-dissociation method works with the His $_{6}$-tag positioned on Scc4 instead of Scc1. Figure 4 shows an SDSPAGE gel of the coexpression and copurification of $\mathrm{His}_{6}$-Scc4-Scc1-FT. In contrast to the ratio of coexpressed tag-free Scc4 and Scc1-His 6 , coexpression of $\mathrm{His}_{6}$-Scc4 and Scc1-FT produced similar quantities of protein (approximately 1:1) (Figure 4, lanes 1 and 2). In the purification shown in Figure 4, the yield was high enough to saturate the Ni-IMAC resin, and the residual complex was present in the lysate flow-through (Figure 4, lane5) and wash (Figure 4, lane 6) samples. The excess complex was recovered using fresh Ni-IMAC resin. Similar to the purified Scc4-Scc1-His 6 complex, the His ${ }_{6}-\mathrm{Scc} 4-\mathrm{Scc} 1-\mathrm{FT}$ complex copurifies in a 1:1 molar ratio (Figure 4, lane 7). The overall yield of $\mathrm{His}_{6}{ }^{-S c c 4-S c c 1-F T}$ is higher than Scc4-Scc1-His 6 at 20-24 mg of complex per L culture in LB medium.

To demonstrate that the sarkosyl-dissociation method works with an interchanged $\mathrm{His}_{6}$-tag, purified $\mathrm{His}_{6}{ }_{6}$ Scc4-Scc1-FT (Figure 5, lane 2) was captured on Ni-IMAC resin and washed with $0.5 \%$ sarkosyl buffer. Scc1-FT eluted in $0.5 \%$ sarkosyl buffer with residual $\mathrm{His}_{6}$-Scc4 (Figure 5, lane 4). Similar to the residual elution of Scc1-His 6 with tag-free Scc4, the residual $\mathrm{His}_{6}{ }_{-} \mathrm{Scc} 4$ was removed by passing the sample through fresh Ni-IMAC resin (data not shown). The remaining immobilized $\mathrm{His}_{6}{ }_{-} \mathrm{Scc} 4$ was eluted in $500 \mathrm{mM}$ imidazole buffer (Figure 5, lane 5). The imidazole elution sample shows complete dissociation of the complex, but the sample also contains the typical background $E$. coli proteins that nonspecifically bind Ni-IMAC. ${ }^{30}$ The background $E$. coli proteins are a common problem with Ni-IMAC, but the absence of these background proteins in the sarkosyl elution of Scc1FT (Figure 5, lane 4) demonstrates an inherent advantage of the sarkosyl-dissociation method compared to standard Ni-IMAC. Because the sarkosyl buffer does not disrupt the interactions between the Ni-IMAC resin and the $\mathrm{His}_{6}$-tagged protein or the background $E$. coli proteins, the sarkosyl-eluted tag-free or non-His 6 -tagged protein is free of these background proteins.

An unanticipated advantage of the sarkosyl-dissociation method is Scc1-FT is soluble when it is purified from the $\mathrm{His}_{6}-\mathrm{Scc} 4-\mathrm{Scc} 1-\mathrm{FT}$ complex. When Scc1-His 6 and Scc1-FT are expressed alone, the proteins are mostly insoluble (Figure S7), ${ }^{13}$ and Scc1-His ${ }_{6}$ dissociated from the Scc4-Scc1-His 6 complex was only soluble in high-imidazole Tris buffer. Even though sarkosyl is commonly used to solubilize inclusion bodies and coaggregated proteins, 24,31,32 these methods did not solubilize Scc1-FT (expressed alone) from the lysed cell pellet (Figure S7). In contrast, dissociated Scc1-FT was soluble in sodium phosphate or Tris buffer (at $\mathrm{pH}$ 7-8) even after sarkosyl was removed. Purified $\mathrm{His}_{6}$-Scc4-Scc1-FT complex or lysate containing the coexpressed complex can be used for on-column complex dissociation of Scc1-FT with yields of 12-15 mg of protein per L culture in LB medium. Access to soluble 
Scc1-FT allows, for the first time, the investigation of Scc4 and Scc1 complex formation and binding kinetics, which is currently being pursued in our laboratory.

\section{Validation of the Tag-Free Scc4 Structure.}

Because sarkosyl has the potential to disrupt the tertiary structure of $S c c 4,2 \mathrm{D}{ }^{1} \mathrm{H}_{-}{ }^{15} \mathrm{~N}$ HSQC NMR was used to compare the backbone structures of Scc4 exposed to sarkosyl and His $_{6}$-Scc4 expressed alone and purified without sarkosyl. Two samples of Scc4 exposed to sarkosyl are (i) tag-free Scc4 eluted in 0.5\% sarkosyl buffer from the captured Scc4-Scc1-

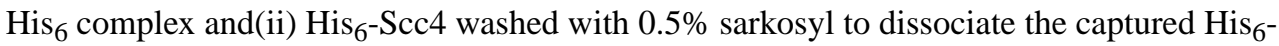
Scc4-Scc1-FT complex. The sarkosyl-washed $\mathrm{His}_{6}$-Scc4 will be indicated with an asterisk (His 6 -Scc4*) to avoid confusing it with the $\mathrm{His}_{6}$-Scc4 sample that was not exposed to sarkosyl. Even though sarkosyl has been shown to retain the activity of some enzymes, 23-25,32 tag-free Scc4 in $0.5 \%$ sarkosyl was immediately diluted to $0.1 \%$ to avoid any negative effects on the native structure. Diluting the sarkosyl to $0.1 \%$ disrupts the micelles and allows for the removal of sarkosyl using dialysis tubing or centrifugal filters. $1 \mathrm{D}^{1} \mathrm{H}$ NMR was used to verify the absence of sarkosyl in the Scc4 NMR samples (data not shown). Figure $6 \mathrm{~A}$ shows the $1 \mathrm{H}^{-15} \mathrm{~N}$ HSQC spectrum of $0.3 \mathrm{mM} \mathrm{His}_{6}-\mathrm{Scc}^{1} *$ in $50 \mathrm{mM}$ sodium phosphate, $10 \% \mathrm{D}_{2} \mathrm{O}, 50 \mu \mathrm{M}$ DSS, $\mathrm{pH} 7.3$ buffer with 64 scans using a Bruker AVIII $500 \mathrm{MHz}$. These are the same conditions used to analyze the $0.5 \mathrm{mM} \mathrm{His}_{6}$-Scc4 sample shown in Figure 1. The protein concentrations of these two samples are only different because the yield of $\mathrm{His}_{6}-\mathrm{Scc} 4 *$ was lower than expected for this sample preparation. To compensate for the concentration difference, the maximum contour levels used in each spectrum were scaled to allow for direct comparison. An overlay of the two spectra in Figure $6 \mathrm{~B}$ shows that the peak positions and relative peak intensities are the same, indicating that the backbone structures are the same regardless of exposure to $0.5 \%$ sarkosyl. If the structure of $\mathrm{His}_{6}$-Scc $*$ changes in the presence of sarkosyl, then the effect is reversible. It is interesting that the backbone structure of $\mathrm{His}_{6}-\mathrm{Scc}_{4} *$ is not different from $\mathrm{His}_{6}$-Scc4 considering $\mathrm{His}_{6}$-Scc4* was originally in complex with Scc1-FT. This observation does not exclude the possibility of a different Scc4 structure when in complex with Scc1, but it suggests that the free form of Scc4 is independent of its origin. In the context of Scc4's dual functions in CT, these data suggest that the in vivo origin of free Scc4 acting as a transcription factor could arise from the dissociation of the Scc4-Scc1 complex or expression of Scc4.

The ${ }^{1} \mathrm{H}_{-}{ }^{15} \mathrm{~N}$ HSQC spectrum of tag-free Scc4 in Figure 7A shows that tag-free Scc4 is a good candidate for NMR structure determination. Comparing the spectra of tag-free Scc4 and $\mathrm{His}_{6}$-Scc4 (overlaid in Figure 7B) shows that most of the peak positions are the same, indicating that the backbone structure of tag-free Scc4 is similar to $\mathrm{His}_{6}$-Scc4 despite being exposed to sarkosyl. Some peak positions are expected to be different due to the presence of the $\mathrm{His}_{6}$-tag, which can alter the chemical shifts of local nuclei. There are no apparent effects from sarkosyl on the backbone structure of tag-free Scc4. The spectrum of tag-free Scc4 has better features than the $\mathrm{His}_{6}$-Scc4 spectrum. In Figure 7B, the contour level is adjusted by a factor of 2 for tag-free Scc 4 to compensate for the 4-fold difference in the number of signal-averaged scans (16 scans for tag-free Scc4 and 64 scans for $\mathrm{His}_{6}{ }_{-} \mathrm{Scc} 4$ ). This adjustment allows a direct comparison of the signals. The sharp peaks in both spectra, 
corresponding to the side-chain amide groups and the $C$-terminal amide, have similar signalto-noise ratios, but the broad peaks from other backbone amide groups in the $\mathrm{His}_{6}$-Scc4 spectrum are sharper with higher intensity in the tag-free Scc4 spectrum (Figure 7C). The more uniform peak intensities of tag-free Scc4 increases the peak-to-peak resolution and reduces the number of scans needed for signal averaging, which is especially important to minimize the instrument time used to collect data for high-resolution structure determination. Over $90 \%$ of the expected backbone amide $(\mathrm{N}-\mathrm{H})$ correlation peaks are visible for tag-free Scc4, compared to only $75 \%$ for $\mathrm{His}_{6}$-Scc4, so determining the NMR structure of tag-free Scc4 is feasible and currently in progress.

\section{CONCLUSIONS}

A method to produce tag-free Scc4, an RNA polymerase binding protein from $C T$, was developed by dissociating the E. coli-expressed CTT3SS chaperone complex, Scc4-Scc1, with sarkosyl while immobilized on Ni-IMAC resin. Developing this method specifically for Scc4 was important because affinity purification tags caused adverse effects that were problematic for NMR structural studies. A direct-capture affinity method using immobilized Scc1-His 6 or Scc1-FT to capture tag-free Scc4 was not possible because these Scc1constructs are not soluble when expressed alone. Scc1-His 6 is soluble when coexpressed with tag-free Scc4, and the immobilized Scc1-His ${ }_{6}$ from the complex can be used to directly capture excess tag-free Scc4 from the lysate. Using sarkosyl as a nondenaturing detergent, tag-free Scc4 was produced in higher yield and with better characteristics for NMR structure determination compared to $\mathrm{His}_{6}$-Scc4. The sarkosyl did not alter the backbone structure of Scc4 or interfere with the nickel-His 6 -tag interaction. The method was also successful in purifying Scc1-FT by interchanging the $\mathrm{His}_{6}{ }_{-}$-tag to Scc4. In our study, Scc1-FT expressed alone could not be recovered, even with sarkosyl buffer, but soluble Scc1-FT was produced using the coexpressed complex, His $_{6}$-Scc4-Scc1-FT, and the sarkosyl-dissociation method.

The sarkosyl-dissociation method can be applied to other protein complexes based on the reported uses of sarkosyl for protein recovery and purification ${ }^{23-29,31,32}$ and the results presented herein. The method is limited to protein complexes with high-affinity such that the immobilized complexes can be washed without leaching the protein of interest. The method is especially useful when the protein of interest is insoluble without its partner or when affinity tags and protease cleavage sites lead to undesirable properties. In addition to the primary advantage of producing tag-free proteins, dissociating the complex and eluting the protein of interest with sarkosyl has an additional advantage, compared to eluting His $_{6}$ tagged proteins with imidazole, because the contaminating E. coli proteins with affinity for $\mathrm{Ni}$-IMAC resin do not elute with sarkosyl and the tag-free protein. Alternating the position of the His $_{6}$-tag allows different proteins in the complex to be purified as demonstrated with the Scc4-Scc1-His 6 and $\mathrm{His}_{6}$-Scc4-Scc1-FT complexes. This feature allows each protein in a complex to be produced tag-free (or with a different tag), which offers the potential to assemble a completely tag-free complex. The dissociation method can also be used to make asymmetrically labeled samples, where each subunit has a different isotope pattern; these labeling schemes are important for studying quaternary structures by NMR. ${ }^{33} \mathrm{We}$ are currently applying the sarkosyl-dissociation method to produce asymmetrically labeled Scc4-Scc1 samples for NMR structure determination of the complex. 


\section{Supplementary Material}

Refer to Web version on PubMed Central for supplementary material.

\section{ACKNOWLEDGMENTS}

We thank Dr. Ken Fields for the plasmid, pScc1-FT.

Funding

This work was supported by funding from the National Institutes of Health grant R15GM109413 (M.A.M.) and the Louisiana Biomedical Collaborative Research Program (M.A.M. and L.S.). T.O.U., O.Y.G., and A.C.S. thank the Louisiana State University Department of Chemistry for providing support through teaching assistantships.

\section{ABBREVIATIONS}

T3SS

NMR

sarkosyl

SDS

CT

EBs

RBs

His $_{6}$-tag

Ni-IMAC

HSQC

IPTG

Tris

FPLC

$A_{280}$

SDS-PAGE

cmc

DSS type III secretion system

nuclear magnetic resonance

sodium $N$-lauroylsarcosine

sodium dodecyl sulfate

Chlamydia trachomatis

elementary bodies

reticulate bodies

6X histidine-tag

nickel-charged immobilized metal affinity chromatography

heteronuclear single quantum coherence

isopropyl $\beta$-D-1-thiogalactopyranoside

tris-(hydroxymethyl)aminomethane hydrochloride

fast protein liquid chromatography system

absorbance at $280 \mathrm{~nm}$

sodium dodecyl sulfate-polyacrylamide gel electrophoresis

critical micelle concentration

sodium3-(trimethylsilyl)-1-propanesulfonate

\section{REFERENCES}

(1). Rekart ML, Gilbert M, Meza R, Kim PH, Chang M, Money DM, and Brunham RC (2013) Chlamydia public health programs and the epidemiology of pelvic inflammatory disease and ectopic pregnancy. J. Infect. Dis 207 (1), 30-38 [PubMed: 23100568] 
(2). Lanjouw E, Ossewaarde JM, Stary A, Boag F, and van der Meijden WI (2010) 2010 European guideline for the management of Chlamydia trachomatis infections. Int. J. STD AIDS 21 (11), 729-737. [PubMed: 21187352]

(3). Wattiau P, Woestyn S, and Cornelis GR (1996) Customized secretion chaperones in pathogenic bacteria. Mol. Microbiol 20 (2), 255-262. [PubMed: 8733225]

(4). Stephens RS, Kalman S, Lammel C, Fan J, Marathe R, Aravind L, Mitchell W, Olinger L, Tatusov RL, Zhao Q, Koonin EV, and Davis RW (1998) Genome sequence of an obligate intracellular pathogen of humans: Chlamydia trachomatis. Science 282 (5389), 754-759. [PubMed: 9784136]

(5). Borges V, Pinheiro M, Antelo M, Sampaio DA, Vieira L, Ferreira R, Nunes A, Almeida F, Mota LJ, Borrego MJ, and Gomes JP (2015) Chlamydia trachomatis in vivo to in vitro transition reveals mechanisms of phase variation and down-regulation of virulence factors. PLoS One 10 (7), e0133420. [PubMed: 26207372]

(6). Brunham RC, and Rey-Ladino J (2005) Immunology of Chlamydia infection: Implications for a Chlamydia trachomatis vaccine. Nat. Rev. Immunol 5 (2), 149-161. [PubMed: 15688042]

(7). Kleba B, and Stephens RS (2008) Chlamydial effector proteins localized to the host cell cytoplasmic compartment. Infect. Immun 76 (11), 4842-4850. [PubMed: 18710866]

(8). Elwell C, Mirrashidi K, and Engel J (2016) Chlamydia cell biology and pathogenesis. Nat. Rev. Microbiol 14 (6), 385-400. [PubMed: 27108705]

(9). Fields KA, and Hackstadt T (2000) Evidence for the secretion of Chlamydia trachomatis CopN by a type III secretion mechanism. Mol. Microbiol 38 (5), 1048-1060. [PubMed: 11123678]

(10). Rao X, Deighan P, Hua Z, Hu X, Wang J, Luo M, Wang J, Liang Y, Zhong G, Hochschild A, and Shen L (2009) A regulator from Chlamydia trachomatis modulates the activity of RNA polymerase through direct interaction with the beta subunit and the primary sigma subunit. Genes Dev. 23 (15), 1818-1829. [PubMed: 19651989]

(11). Spaeth KE, Chen Y-S, and Valdivia RH (2009) The Chlamydia type III secretion system C-ring engages a chaperone-effector protein complex. PLoS Pathog. 5 (10), 1-11.

(12). Silva-Herzog E, Joseph SS, Avery AK, Coba JA, Wolf K, Fields KA, and Plano GV (2011) Scc1 (CP0432) and Scc4 (CP0033) function as a type III secretion chaperone for CopN of Chlamydia pneumoniae. J. Bacteriol 193 (14), 3490-3496. [PubMed: 21571996]

(13). Shen L, Macnaughtan MA, Frohlich KM, Cong YG, Goodwin OY, Chou CW, LeCour L, Krup K, Luo M, and Worthylake DK (2015) Multipart chaperone-effector recognition in the Type III secretion system of Chlamydia trachomatis. J. Biol. Chem 290 (47), 28141-28155. [PubMed: 26438824]

(14). Archuleta TL, Du Y, English CA, Lory S, Lesser C, Ohi MD, Ohi R, and Spiller BW (2011) The Chlamydia effector Chlamydial outer protein N (CopN) sequesters tubulin and prevents microtubule assembly. J. Biol. Chem 286 (39), 33992-33998. [PubMed: 21841198]

(15). Huang J, Lesser CF, and Lory S (2008) The essential role of the CopN protein in Chlamydia pneumoniae intracellular growth. Nature 456 (7218), 112-115. [PubMed: 18830244]

(16). Makowska-Grzyska M, Kim Y, Maltseva N, Li H, Zhou M, Joachimiak G, Babnigg G, and Joachimiak A (2014) Protein production for structural genomics using E. coli expression. Methods Mol. Biol 1140, 89-105. [PubMed: 24590711]

(17). Block H, Maertens B, Spriestersbach A, Kubicek J, Schafer F, and Lorsch JR (2015) Proteolytic affinity tag cleavage. Methods Enzymol. 559, 71-97. [PubMed: 26096504]

(18). Goh HC, Sobota RM, Ghadessy FJ, and Nirantar S (2017) Going native: Complete removal of protein purification affinity tags by simple modification of existing tags and proteases. Protein Expression Purif. 129, 18-24.

(19). Fields KA, Fischer ER, Mead DJ, and Hackstadt T (2005) Analysis of putative Chlamydia trachomatis chaperones Scc2 and Scc3 and their use in the identification of type III secretion substrates. J. Bacteriol 187 (18), 6466-6478. [PubMed: 16159780]

(20). Marley J, Lu M, and Bracken C (2001) A method for efficient isotopic labeling of recombinant proteins. J. Biomol. NMR 20(1), 71-75. [PubMed: 11430757]

(21). Studier FW (2005) Protein production by auto-induction in high-density shaking cultures. Protein Expression Purif. 41 (1), 207-234. 
(22). Canchi DR, Paschek D, and García AE (2010) Equilibrium study of protein denaturation by urea. J. Am. Chem. Soc 132 (7), 2338-2344. [PubMed: 20121105]

(23). Wroblewski H, Burlot R, and Johansson K-E (1978) Solubilization of Spiroplasma citri cell membrane proteins with the anionic detergent sodium lauroyl-sarcosinate (sarkosyl). Biochimie 60(4), 389-398. [PubMed: 687677]

(24). Tao H, Liu W, Simmons BN, Harris HK, Cox TC, and Massiah MA (2010) Purifying natively folded proteins from inclusion bodies using sarkosyl, Triton X-100, and CHAPS. BioTechniques 48 (1), 61-64. [PubMed: 20078429]

(25). Rahman S, Arai S, Saijo S, Yamato I, and Murata T (2011) Sarkosyl is a good regeneration reagent for studies on vacuolar-type ATPase subunit interactions in Biacore experiments. Anal. Biochem 418 (2), 301-303. [PubMed: 21806959]

(26). Bordes R, Tropsch J, and Holmberg K (2010) Role of an amide bond for self-assembly of surfactants. Langmuir 26 (5), 3077-3083. [PubMed: 19817350]

(27). Ghosh S, and Dey J (2015) Binding of fatty acid amide amphiphiles to bovine serum albumin: Role of amide hydrogen bonding. J. Phys. Chem. B 119 (25), 7804-7815. [PubMed: 26023820]

(28). Antolini F, Lo Bello M, and Sette M (2003) Purified promyelocytic leukemia coiled-coil aggregates as a tetramer displaying low alpha-helical content. Protein Expression Purif. 29 (1), 94-102.

(29). von Rechenberg M, Blake BK, Ho YSJ, Zhen YJ, Chepanoske CL, Richardson BE, Xu NF, and Kery V (2005) Ampicillin/penicillin-binding protein interactions as a model drug-target system to optimize affinity pull-down and mass spectrometric strategies for target and pathway identification. Proteomics 5 (7), 1764-1773. [PubMed: 15761956]

(30). Schmitt J, Hess H, and Stunnenberg HG (1993) Affinity purification of histidine-tagged proteins. Mol. Biol. Rep 18 (3), 223-230. [PubMed: 8114690]

(31). Frankel S, Sohn R, and Leinwand L (1991) The use of sarkosyl in generating soluble-protein after bacterial expression. Proc. Natl. Acad. Sci. U. S. A 88 (4), 1192-1196. [PubMed: 1705029]

(32). Burgess RR (1996) [12] Purification of overproduced Escherichia coli RNA polymerase $\sigma$ factors by solubilizing inclusion bodies and refolding from sarkosyl. Methods Enzymol. 273, 145-149. [PubMed: 8791607]

(33). Anglister J, Srivastava G, and Naider F (2016) Detection of intermolecular NOE interactions in large protein complexes. Prog. Nucl. Magn. Reson. Spectrosc 97, 40-56. [PubMed: 27888839] 


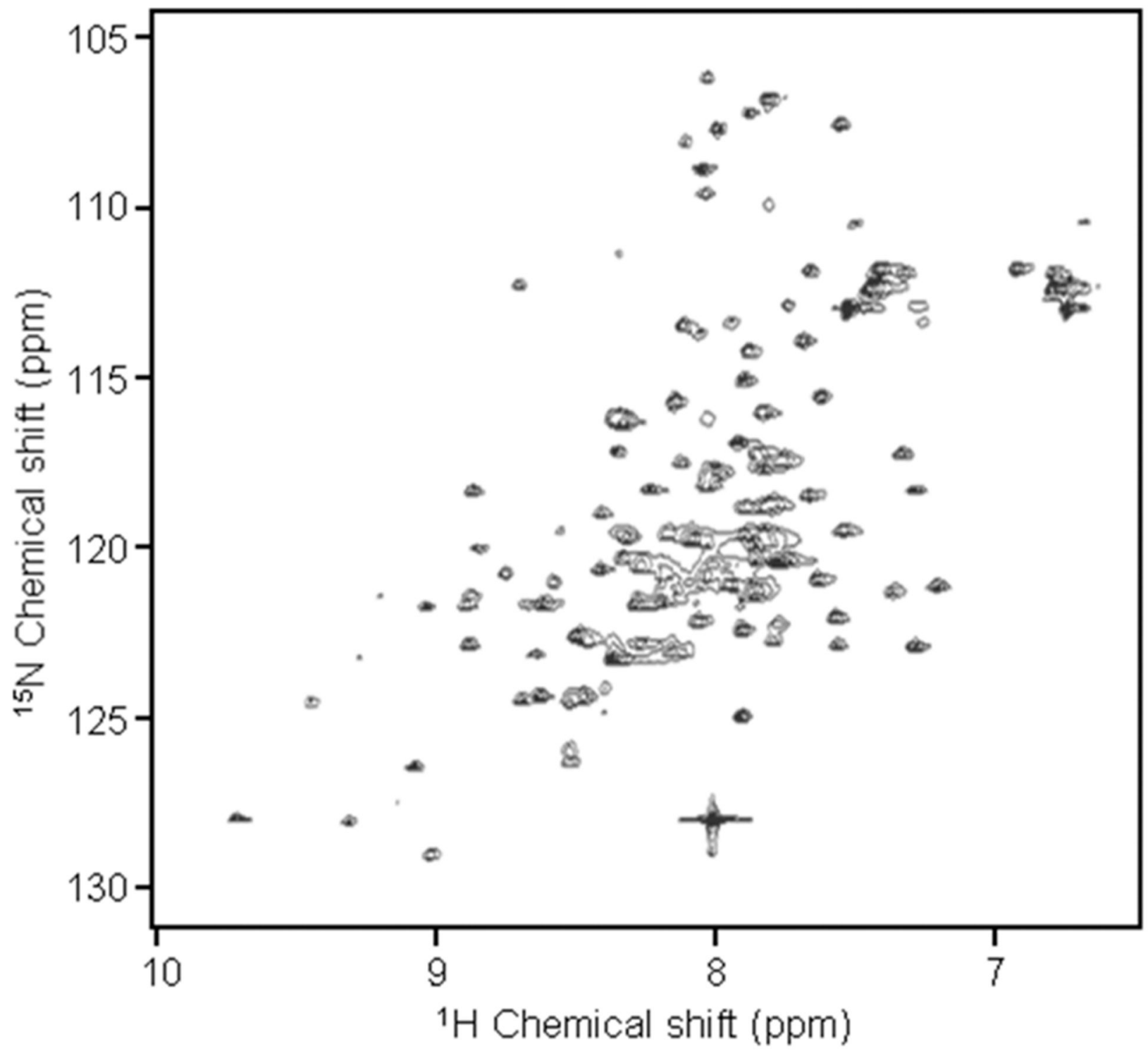

Figure 1.

${ }^{1} \mathrm{H}_{-}{ }^{15} \mathrm{~N}$ HSQC spectrum of $0.5 \mathrm{mM}{ }^{15} \mathrm{~N}$-labeled $\mathrm{His}_{6}$-Scc4 with 64 scans. 


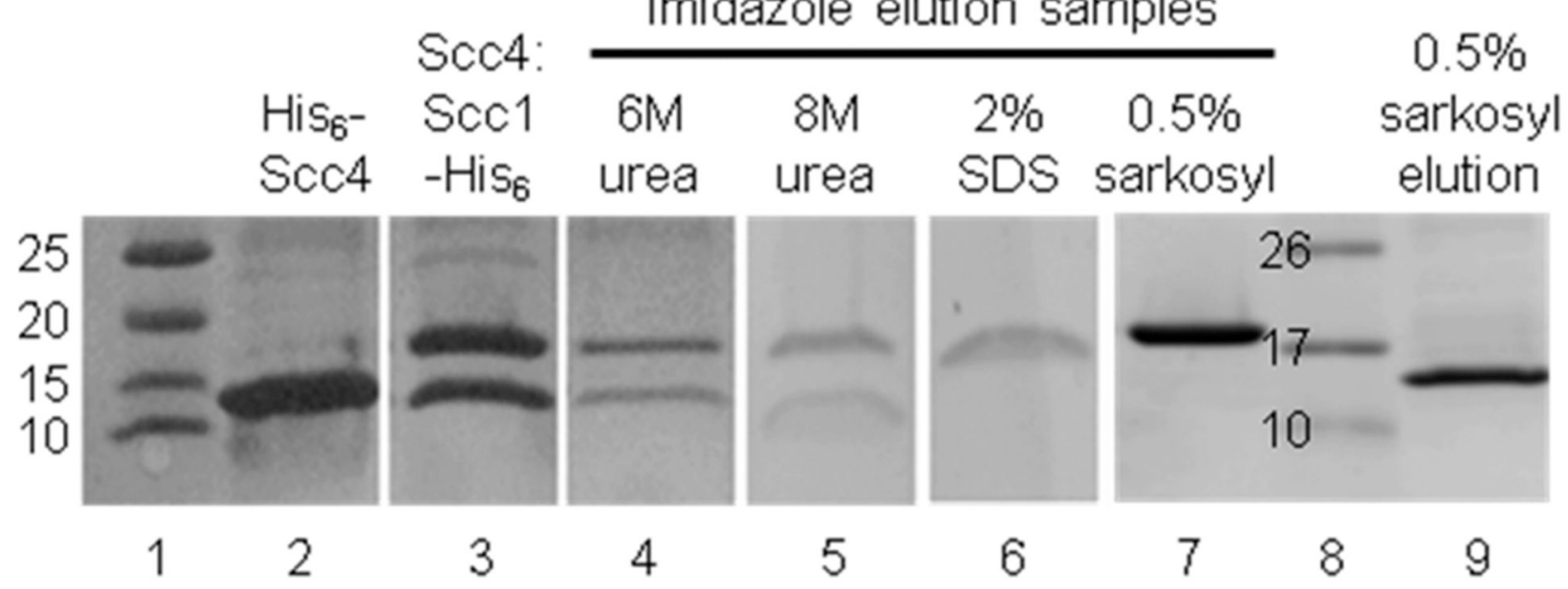

Figure 2.

Various reagents were tested to dissociate the Scc4-Scc1-His 6 complex while it was immobilized on Ni-IMAC resin. Lane numbers are labeled along the bottom. Lane 1 is BioRad Precision Plus protein standards with the molecular weights listed to the left in $\mathrm{kDa}$. Lanes 2 and 3 are positive control samples of purified $\mathrm{His}_{6}-\mathrm{Scc} 4$ and Scc4-Scc1-His 6 complex (Scc4 is $14.7 \mathrm{kDa}$, and $\mathrm{Scc}^{-\mathrm{His}_{6}}$ is $18.8 \mathrm{kDa}$ ). Immobilized Scc4-Scc1-His 6 was washed with various reagents, and the remaining proteins were eluted with $500 \mathrm{mM}$ imidazole buffer. Lanes 4-7 show the imidazole elution samples of immobilized Scc4-Scc1His $_{6}$ washed with $6 \mathrm{M}$ urea, $8 \mathrm{M}$ urea, $2 \%$ SDS, and $0.5 \%$ sarkosyl, respectively. Lane 8 is Fisher BioReagents EZ-Run Rec prestained protein ladder with the molecular weights listed to the left in $\mathrm{kDa}$. Lane 9 is the protein eluted with $0.5 \%$ sarkosyl buffer (counterpart to the imidazole elution sample in lane 7) from the immobilized Scc4-Scc1-His 6 complex. Individual gel images were aligned using the protein ladders as references, and some ladders were removed to improve visualization and comparison. Protein loading was not standardized. The complete gels can be viewed in Figure S4. 


\section{Before After Sarkosyl Removal Desalted IPTG IPTG Elution Scc1-His $\mathrm{Scc4}$}

Imidazole Scc1-His 6
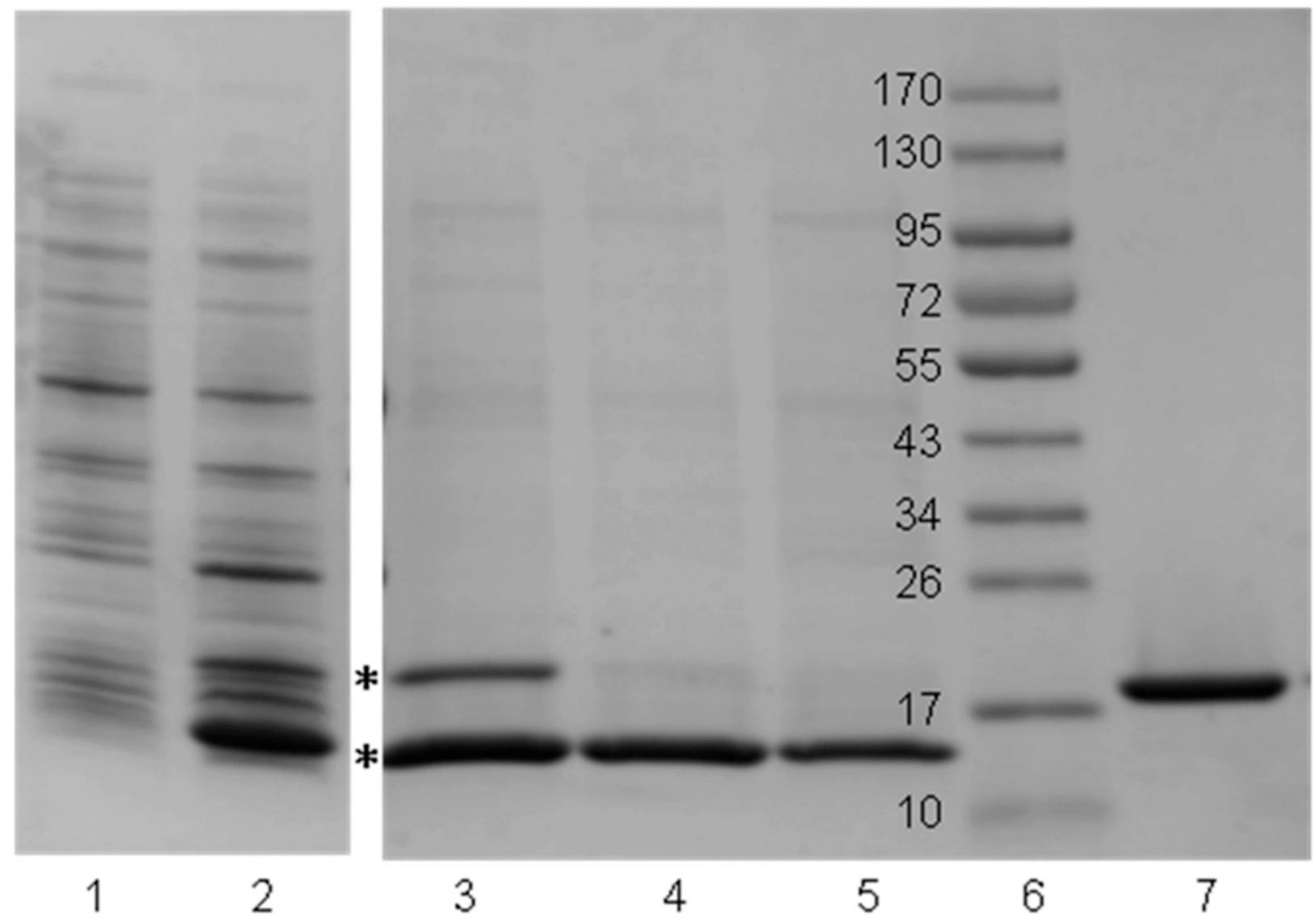

Figure 3.

SDS-PAGE analysis of the expression and purification of tag-free Scc4 from the Scc4-Scc1$\mathrm{His}_{6}$ complex. Lane numbers are labeled along the bottom. Lanes 1 and 2 are the whole cell lysate before and after induction with IPTG showing higher levels of tag-free Scc4 compared to Scc1-His 6 . Asterisks mark tag-free Scc4 (14.7 kDa) and Scc1-His 6 (18.8 kDa). After the Scc4-Scc1-His 6 complex was captured on Ni-IMAC resin and washed with Tris buffer, 0.5\% sarkosyl buffer was used to elute tag-free Scc4 (lane 3) with some Scc1-His 6 coeluting. Lane 4 shows the removal of Scc1-His 6 from the tag-free Scc4 sample, and lane 5 shows the purified tag-free Scc 4 after exchanging the buffer using a $P 4$ gel column. Lane 6 is a Fisher BioReagents EZ-Run Rec prestained protein ladder with the molecular weights listed to the left in $\mathrm{kDa}$. Lane 7 is Scc1-His 6 eluted with imidazole buffer after the elution of tag-free Scc4. The gel images originated from the same gel; several lanes were removed for clarity. 


\section{Before After Cleared Flow- Imidazole IPTG IPTG Pellet lysate through Wash elution}

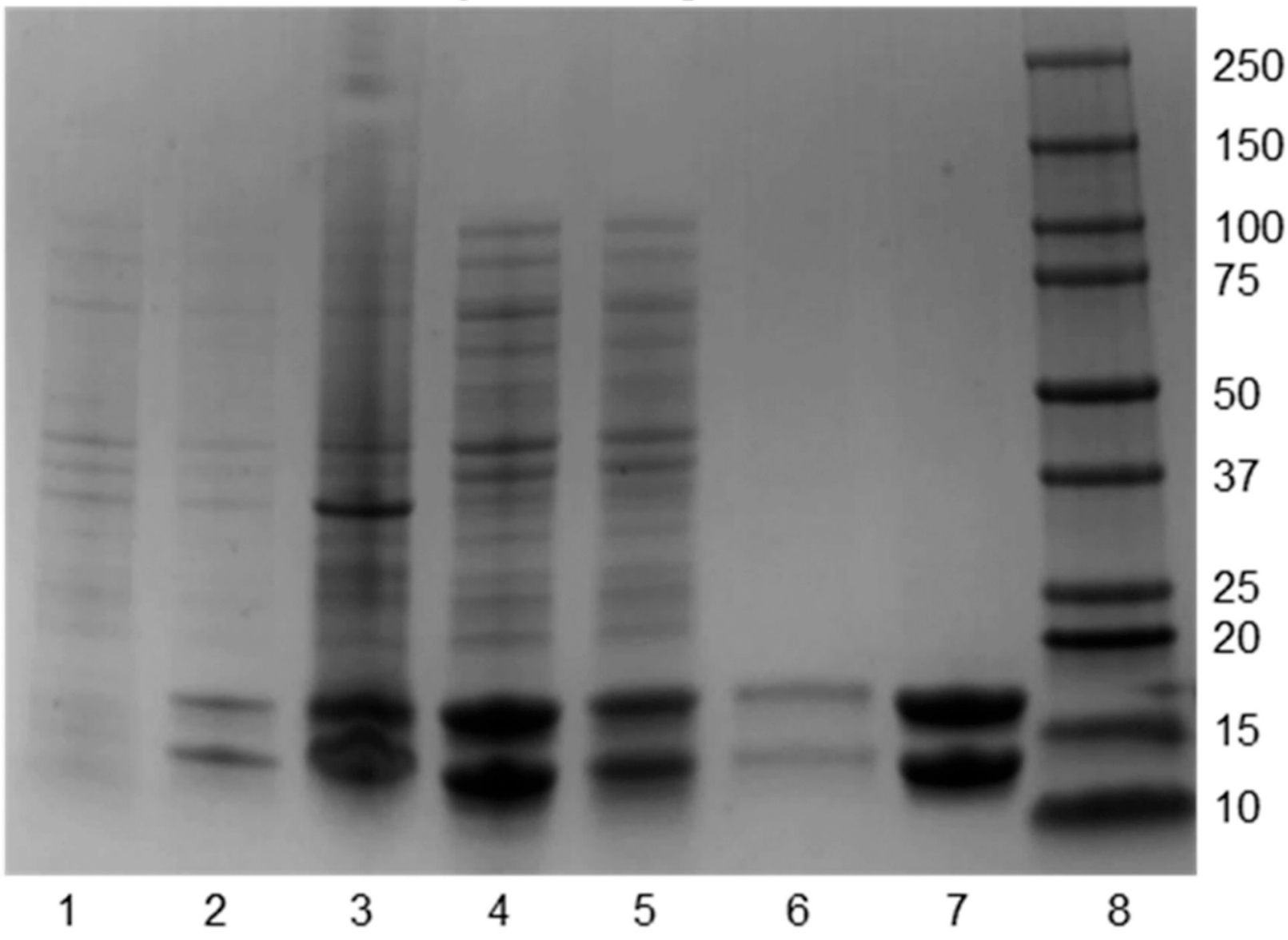

Figure 4.

SDS-PAGE analysis of the expression and purification of the $\mathrm{His}_{6}$-Scc4-Scc1-FT complex. Lane numbers are labeled along the bottom. Lanes 1 and 2 are samples of the culture before and after induction with IPTG showing similar levels of $\mathrm{His}_{6}{ }^{-S c c} 4$ and Scc1-FT expression. Lane 3 is the pellet, and lane 4 is the cleared lysate after cell lysis. The complex was purified using Ni-IMAC resin with the lysate flow-through (lane 5), wash step (lane 6), and elution of the His $_{6}$-Scc4-Scc1-FT complex with imidazole buffer (lane 7). Lane 8 is the Bio-Rad Precision Plus protein standard with the molecular weights listed to the right in $\mathrm{kDa}^{-\mathrm{His}_{6}}{ }^{-}$ Scc4 is $15.8 \mathrm{kDa}$, and Scc1-FT is $18.2 \mathrm{kDa}$. 
$\mathrm{His}_{6}-\mathrm{Scc} 4$ : Scc1-FT
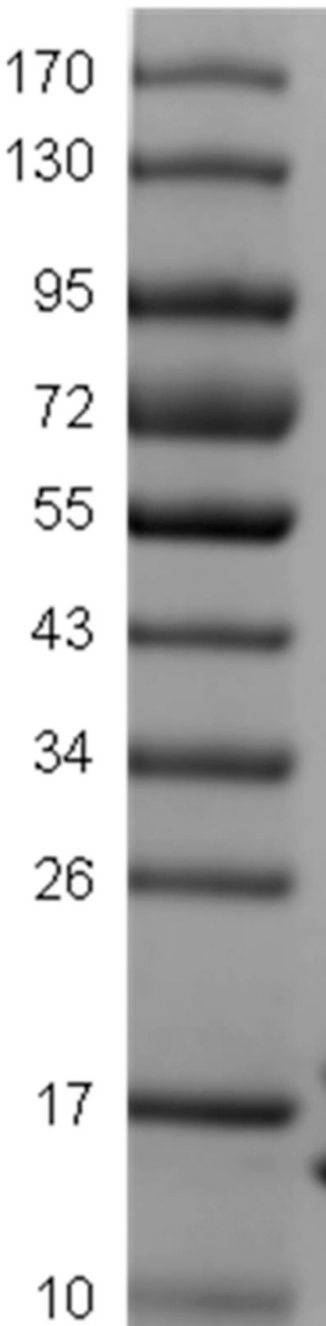

95

72

55

43

34

26

17

10
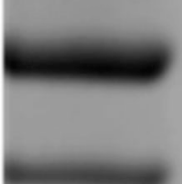

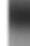
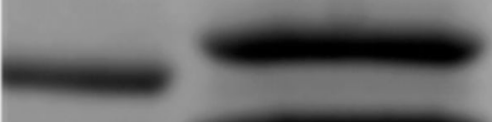

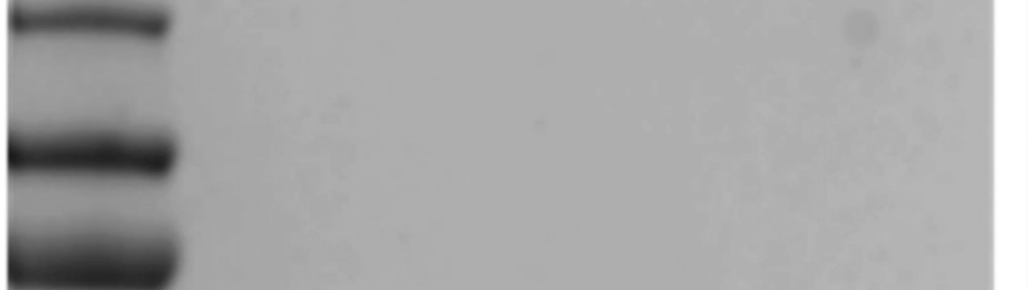

Wash

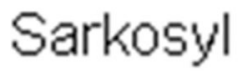
elution

Imidazole elution

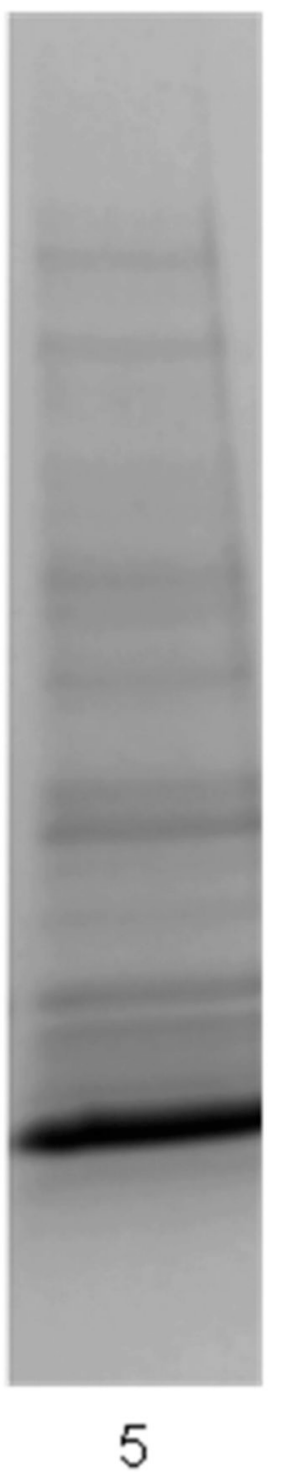

Figure 5.

On-column dissociation of $\mathrm{His}_{6}$-Scc4-Scc1-FT. Lane numbers are labeled along the bottom. Lane 1 is a Fisher BioReagents EZ-Run Rec prestained protein ladder with the molecular weights listed to the left in $\mathrm{kDa}$. Lane 2 is the purified, desalted His6-Scc4-Scc1-FT that was captured on Ni-IMAC resin and washed (lane 3) with buffer ( His $_{6}-\mathrm{Scc} 4$ is $15.8 \mathrm{kDa}$, and Scc1-FT is $18.2 \mathrm{kDa}$ ). Lane 4 shows the sarkosyl-dissociated Scc1-FT, and lane 5 is His $_{6}$ Scc4 eluted with imidazole buffer. The gel images originated from the same gel; several lanes were removed for clarity. 

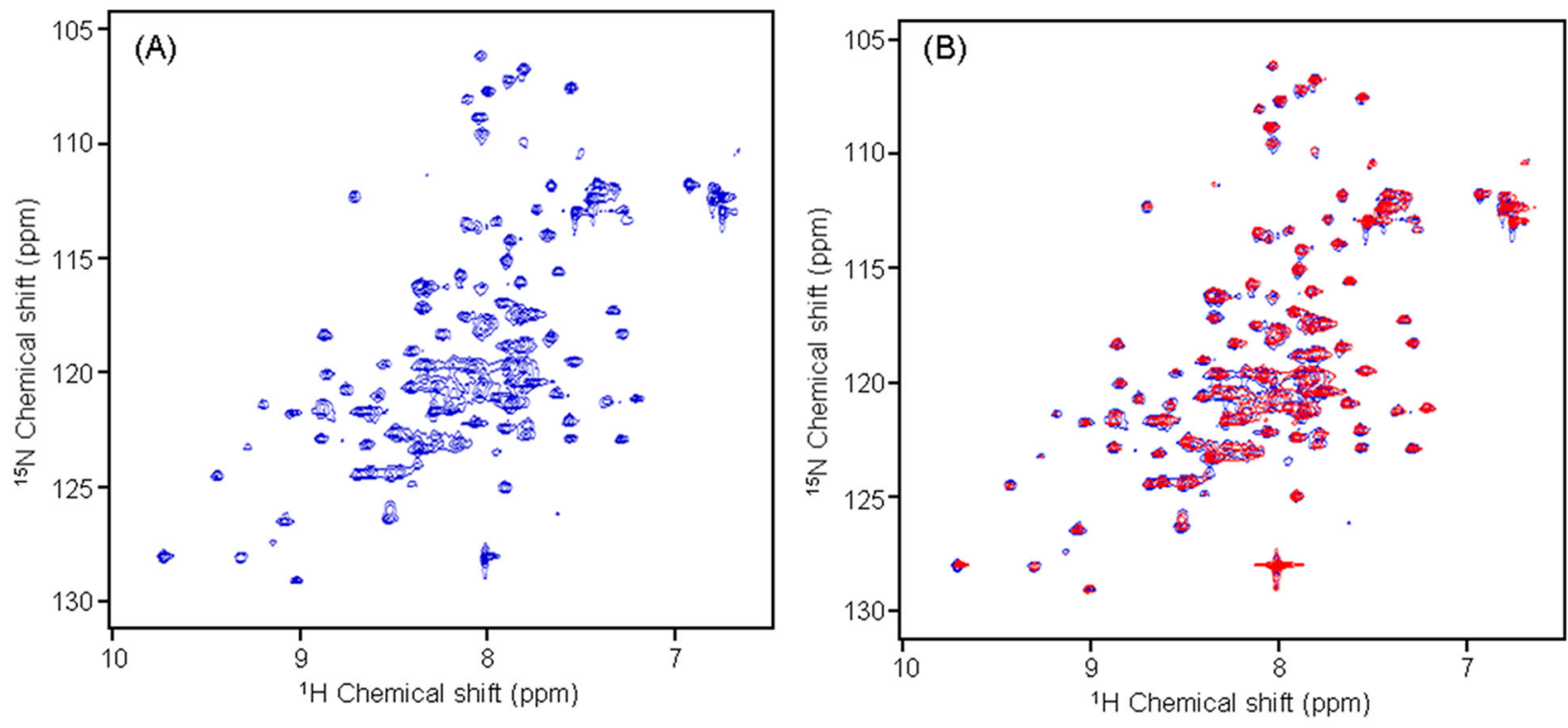

Figure 6.

(A) ${ }^{1} \mathrm{H}^{-15} \mathrm{~N}$ HSQC spectrum of $0.3 \mathrm{mM} \mathrm{His} 6$-Scc $4 *$ with 64 scans. (B) An overlay of ${ }^{1} \mathrm{H}_{-}{ }^{15} \mathrm{~N}$ HSQC spectra of $0.3 \mathrm{mM} \mathrm{His}_{6}$-Scc4* (64 scans, blue) and $0.5 \mathrm{mM} \mathrm{His}_{6}$-Scc4 (64 scans, red) with the same buffer and instrument conditions. 

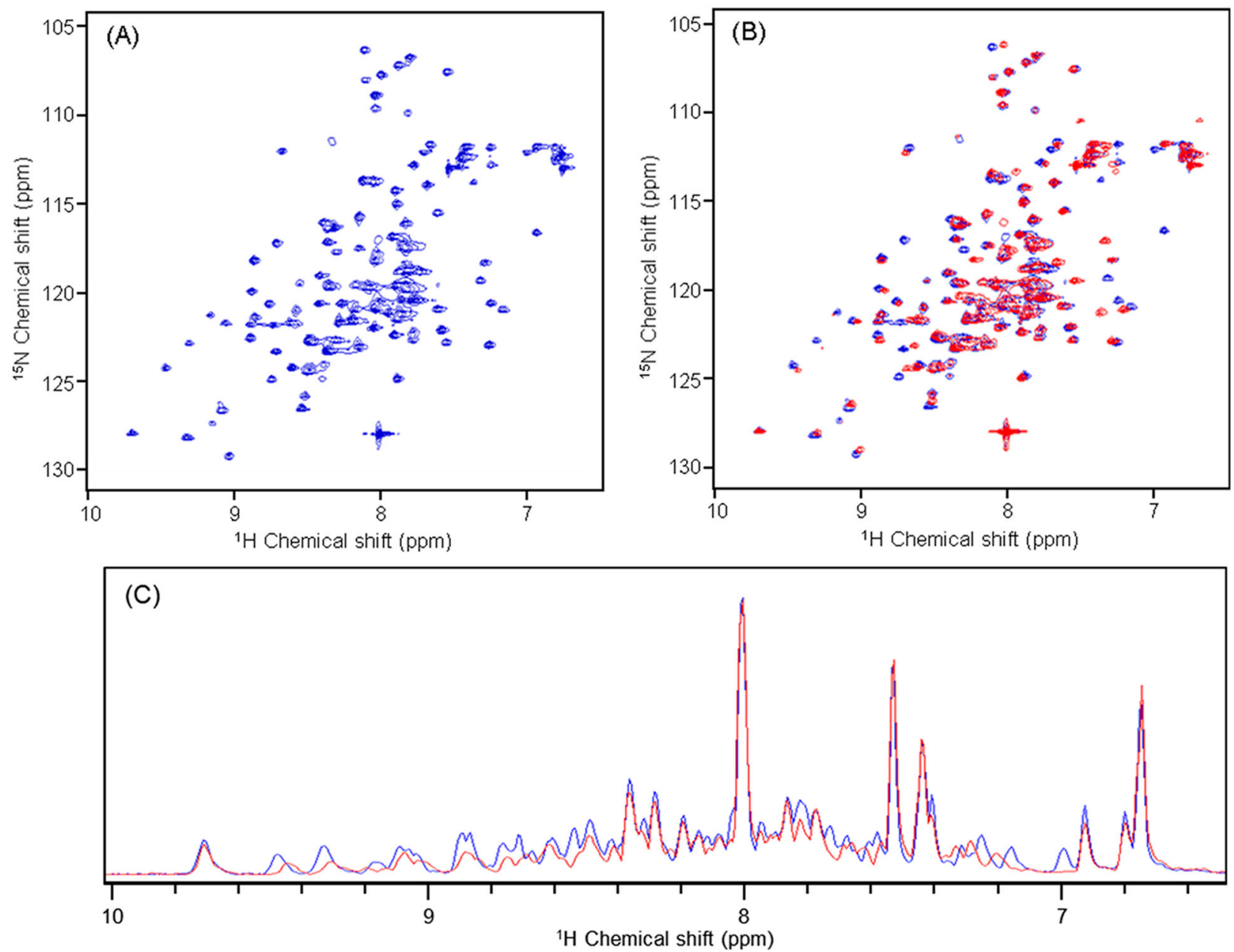

Figure 7.

(A) ${ }^{1} \mathrm{H}^{-15} \mathrm{~N}$ HSQC spectrum of $0.5 \mathrm{mM}$ tag-free Scc4 with 16 scans. (B) An overlay of ${ }^{1} \mathrm{H}_{-}{ }^{15} \mathrm{~N}$ HSQC spectra of $0.5 \mathrm{mM}$ tag-free Scc4 (16 scans, blue) and $0.5 \mathrm{mM} \mathrm{His}_{6}$-Scc4 (64 scans, red) with the same buffer and instrument conditions. (C) 1D projections of the ${ }^{1} \mathrm{H}$ dimension from the overlaid spectra in panel B. 